Article

\title{
Effects of Adding Neutralized Red Mud on the Hydration Properties of Cement Paste
}

\author{
Sukpyo Kang ${ }^{1}$, Hyeju Kang ${ }^{2, *(1)}$ and Byoungky Lee ${ }^{3}$ \\ 1 Department of Architecture, Woosuk University, Jincheon 27841, Korea; ksp0404@woosuk.ac.kr \\ 2 Department of Construction Engineering, Woosuk University, Jincheon 27841, Korea \\ 3 COCHEMS Co., Ltd. Industrial Tools Circulating Center, 160, Daehwa-ro, Daedeok-gu, \\ Daejeon 34368, Korea; fluolbk@naver.com \\ * Correspondence: leekang02@nate.com; Tel./Fax: +82-43-531-2903
}

Received: 27 July 2020; Accepted: 11 September 2020; Published: 16 September 2020

\begin{abstract}
Red mud is a highly alkaline waste by-product of the aluminum industry. Although recycling of red mud is being actively researched, a feasible technological solution has not been found yet. In this study, we propose that neutralization of red mud alkalinity could assist in its use as a construction material. Neutralized red mud (LRM + S; pH 6-8) was prepared by adding sulfuric acid to liquefied red mud (LRM; $\mathrm{pH} 10-12$ ). After adding LRM and LRM $+\mathrm{S}$ to cement paste, the heat of hydration, compressive strength, and hydration products were examined. The experiments revealed that the calorific value of the cement paste with LRM was low, and its peak was delayed, when compared with that of plain cement paste (referred to as Plain), whereas the calorific value of the cement paste with LRM $+S$ was similar to that of Plain. At the age of $28 d$, the compressive strength of the cement paste with $10 \%$ LRM + S was $99 \%$ whereas that with $20 \%$ LRM was only $55 \%$ of the strength of Plain. Thus, our results help to resolve the issue of strength degradation of cementitious materials observed upon the addition of red mud and enable its reuse as a construction material.
\end{abstract}

Keywords: red mud; liquefied red mud; neutralized red mud; cement paste; heat of hydration; compressive strength; $\mathrm{X}$-ray diffraction; recycling

\section{Introduction}

The development of industrial and mass-production processes has resulted in an increased generation of waste, and the disposal of such waste has been recognized as a serious environmental issue. The development of recycling technologies to convert large quantities of waste into natural materials may provide opportunities to mitigate the waste-management problem [1]. Red mud is a reddish-brown sludge by-product generated through the Bayer process in the aluminum industry. When producing 1.0 ton of alumina, 1.0-1.5 tons of red mud is generated as a by-product [2,3]. The chemical components of red mud are $\mathrm{Al}_{2} \mathrm{O}_{3}(17 \%-20 \%), \mathrm{Fe}_{2} \mathrm{O}_{3}(48 \%-54 \%), \mathrm{SiO}_{2}(4 \%-6 \%), \mathrm{TiO}_{2}$ $(3 \%-4 \%), \mathrm{Na}_{2} \mathrm{O}(3 \%-5 \%)$, and $\mathrm{CaO}(1 \%-2 \%)$ [3]. The disposal of red mud is becoming a major problem for industries, as it can lead to soil and water pollution owing to its high alkalinity [4].

Every year, 660 million tons of red mud is estimated to be generated worldwide due to aluminum and its ancillary industries [5,6]. While the processing and recycling of red mud has been a subject of active research, no feasible technology has yet been developed [7]. Meanwhile, 280,000 tons of red mud is currently being annually generated in South Korea, and the recycling rate is less than $10 \%$, thereby requiring the development of a technology that can recycle large quantities of red mud. In South Korea, red mud is designated as a general waste according to the Enforcement Regulations of Waste Management Act [8]. In the construction industry, it can be reused as a cement admixture material in cement, concrete, ready-mixed concrete, and ceramic products. 
While the construction industry can help recycle red mud in large quantities; however, an analysis of the strength characteristics of red mud is important before it can be utilized as a construction material. Previous studies have reported that adding red mud to cement paste and mortar increases their compressive strengths [6,9]. This is thought to be due to the slight pozzolanic reaction and the matrix filling effect of fine red mud particles. On the other hand, Ribeiro et al. mentioned that replacing $35 \%$ and $50 \%$ of cement with red mud reduced compressive strength by approximately $23 \%$ and $64 \%$, respectively, compared to the standard sample. They reported that this is due to the limited hydration characteristics of red mud [1].

Moreover, owing to its high $\mathrm{Fe}_{2} \mathrm{O}_{3}$ content, red mud can also be utilized as a red pigment. Korean regulations specify that red mud can be recycled as a pigment and a coloring agent. Accordingly, some of the red mud generated in South Korea is recycled as a coloring agent. In the recycling process, red mud is dried and crushed, whereby its moisture content, of $30-50 \mathrm{wt} \%$ at the time of discharge, is reduced to less than $10 \mathrm{wt} \%$ [10]. Consequently, a large amount of additional energy is required for this process, thereby increasing the overall recycling cost. Previously, with the intention of reducing the recycling cost of red mud, the authors of this study studied the production of liquefied red mud (LRM) by adding water to red mud with $36 \%$ moisture content such that it may be recycled as a cement concrete material. However, the results of the study revealed that the addition of LRM to cement concrete lowered the strength of the concrete [11]. The decreased compressive strength with increase in alkali content was in agreement with previous findings from literature, and it was attributed to the porous microstructure and lower strength of the alkali-containing $\mathrm{C}-\mathrm{S}-\mathrm{H}$ gel of hardened concrete developed in the high-alkali condition [12].

Therefore, we wanted to examine whether the neutralization of LRM could solve the reduction of concrete strength, using LRM derived from prior research results. In this study, in an attempt to improve the strength degradation observed earlier, we neutralized LRM to reduce its high $\mathrm{pH}$ (from 10-12 to 6-7). For experimental validation, we compared added LRM and neutralized LRM (LRM + S) to cement paste and examined the heat of hydration, compressive strength, and hydration products of the samples using X-ray diffraction (XRD). We expect the results of our study to contribute to an increase in the recycling of red mud as a construction material.

\section{Experimental Program}

\subsection{Materials}

In this study, LRM and neutralized red mud $(L R M+S)$ were prepared using red mud sludge (KC, Korea). LRM was prepared by mixing red mud sludge, water, a thickener, and an antifoamer in the ratio of 1:0.2:0.0036:0.0014 based on the mass of the red mud sludge with a moisture content of approximately $36 \mathrm{wt} \%$. The red mud sludge was first mixed with water for approximately $3 \mathrm{~min}$ using a homomixer, as illustrated in Figure 1. The thickener and antifoamer were then added and mixed for 2 min to improve the storage stability [11].

$\mathrm{LRM}+\mathrm{S}$ was prepared by adding sulfuric acid (95\% purity) to LRM with a $\mathrm{pH}$ of 11.5 such that the $\mathrm{pH}$ could be maintained at 6-8 after a day.

Table 1 details the physical properties of LRM and LRM + S. The $\mathrm{pH}$ values of LRM and LRM + S were 11.5 and 6.7, respectively. Table 2 and Figure 2 present the results of X-ray fluorescence (XRF) and XRD analyses of LRM and LRM $+\mathrm{S}$, respectively. As shown in Table 2, the $\mathrm{SO}_{3}$ content of $\mathrm{LRM}+\mathrm{S}$ was approximately $4.19 \%$ higher than that of LRM owing to the addition of sulfuric acid. Figure 2 shows that the main compounds of LRM are quartz, calcite, boehmite, and hematite [13]. These compounds were also observed in LRM + S. For LRM + S, characteristic peaks were observed at $2 \theta=25.5$ and 51.1 (estimated to be representative of gypsum and sodium sulfate, respectively) owing to the addition of sulfuric acid. 
Ordinary portland cement (OPC, KS L 5201) was used in this study, and its physical and chemical properties are presented in Table 3. The compressive strength of cement was $29.5 \mathrm{MPa}$ at the age of $3 \mathrm{~d}$, $43.8 \mathrm{MPa}$ at the age of $7 \mathrm{~d}$, and 58.9 $\mathrm{MPa}$ at the age of $28 \mathrm{~d}$.

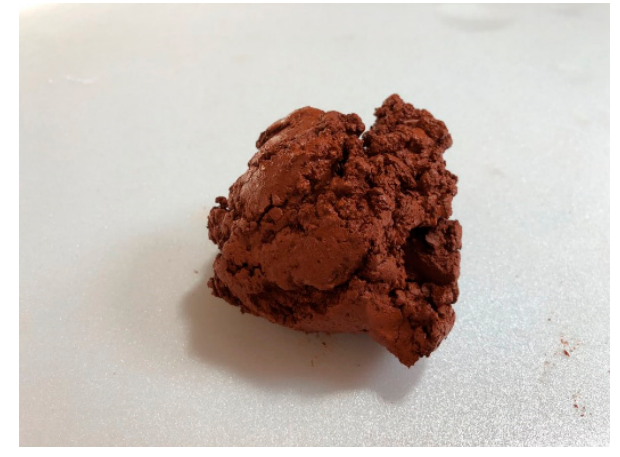

(a) Red mud sludge (moisture content: $36 \mathrm{wt} \%$ )

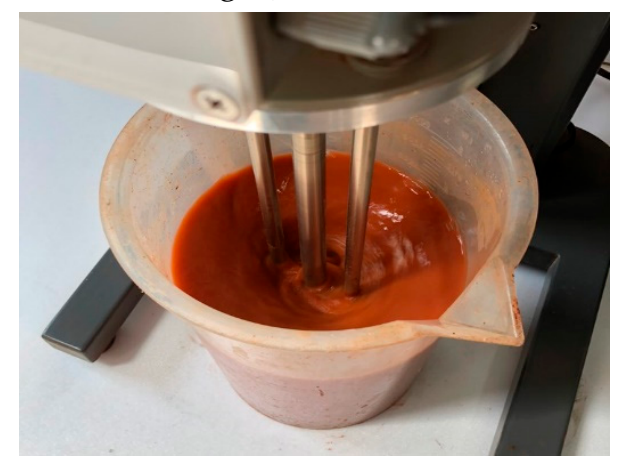

(c) Red mud and water mix

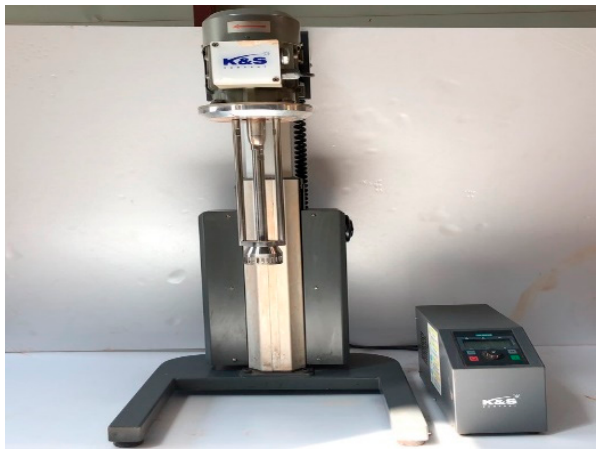

(b) Mixing equipment

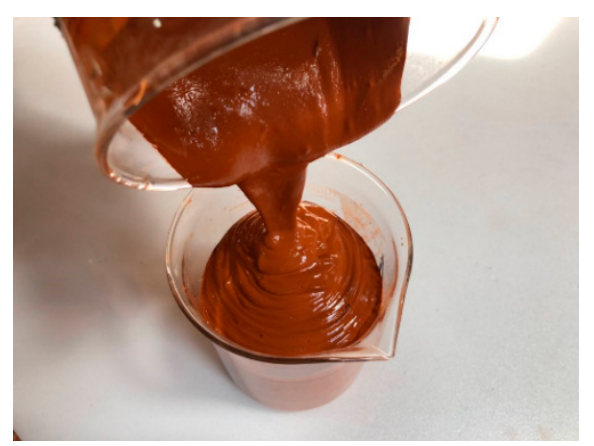

(d) Liquefied red mud

Figure 1. Manufacturing process of liquefied red mud.

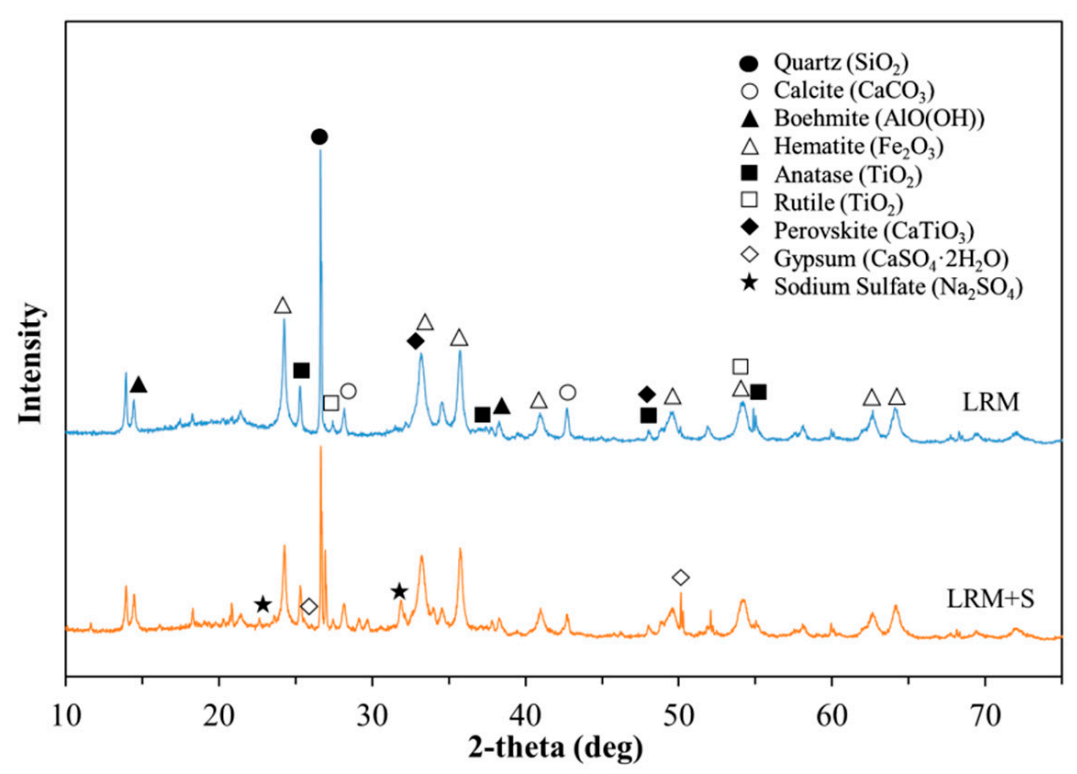

Figure 2. XRD patterns of LRM and LRM + S. 
Table 1. Physical properties of red mud.

\begin{tabular}{ccccccc}
\hline $\begin{array}{c}\text { Type of Red } \\
\text { Mud }\end{array}$ & $\begin{array}{c}\text { Moisture } \\
\text { Content } \\
(\mathbf{\%})\end{array}$ & $\mathbf{p H}$ & $\begin{array}{c}\text { Density } \\
\left(\mathbf{g} / \mathbf{c m}^{\mathbf{3}}\right)\end{array}$ & $\begin{array}{c}\text { Specific } \\
\text { Surface } \\
\text { Area }\left(\mathbf{c m}^{\mathbf{2}} / \mathbf{g}\right)\end{array}$ & $\begin{array}{c}\text { Average } \\
\text { Particle } \\
\text { Diameter }(\boldsymbol{\mu m})\end{array}$ & $\begin{array}{c}\text { Viscosity } \\
\mathbf{( c P )}\end{array}$ \\
\hline $\mathrm{LRM}^{*}$ & 49.5 & 11.5 & 1.5 & 2353 & 2.75 & 42,550 \\
$\mathrm{LRM}+\mathrm{S}^{* *}$ & 49.2 & 6.7 & 1.54 & 2353 & 2.75 & 45,250 \\
\hline
\end{tabular}

${ }^{*}$ LRM: Liquefied red mud; ${ }^{* *}$ LRM + S: Liquefied red mud + sulfuric acid.

Table 2. Chemical composition of red mud.

\begin{tabular}{ccccccccc}
\hline Type of Red Mud & $\mathrm{SiO}_{2}$ & $\mathrm{A1}_{2} \mathrm{O}_{3}$ & $\mathrm{Fe}_{2} \mathrm{O}_{3}$ & $\mathrm{MgO}$ & $\mathrm{Na}_{2} \mathrm{O}$ & $\mathrm{CaO}$ & $\mathrm{TiO}_{2}$ & $\mathrm{SO}_{3}$ \\
\hline LRM & 17.6 & 25.6 & 30.4 & 0.21 & 13.2 & 1.83 & 6.27 & 0.29 \\
\hline $\mathrm{LRM}+\mathrm{S}$ & 17 & 25.4 & 29.2 & 0.21 & 10.7 & 1.84 & 5.99 & 4.48 \\
\hline
\end{tabular}

Table 3. Physical properties and chemical composition of OPC.

\begin{tabular}{|c|c|c|c|c|c|c|c|c|c|c|c|}
\hline \multirow[b]{2}{*}{ Type } & \multirow{2}{*}{$\begin{array}{l}\text { Blaine } \\
\left(\mathrm{cm}^{2} / \mathrm{g}\right)\end{array}$} & \multicolumn{2}{|c|}{ Setting Time } & \multirow{2}{*}{$\begin{array}{l}\text { Density } \\
\left(\mathrm{g} / \mathrm{cm}^{3}\right)\end{array}$} & \multicolumn{7}{|c|}{ Chemical Composition (\%) } \\
\hline & & $\begin{array}{c}\text { Initial } \\
\text { (min) }\end{array}$ & $\begin{array}{l}\text { Final } \\
\text { (min) }\end{array}$ & & $\mathrm{SiO}_{2}$ & $\mathrm{Al}_{2} \mathrm{O}_{3}$ & $\mathrm{Fe}_{2} \mathrm{O}_{3}$ & $\mathrm{CaO}$ & $\mathrm{MgO}$ & $\mathrm{SO}_{3}$ & $\begin{array}{c}\text { lg. } \\
\text { Loss }\end{array}$ \\
\hline $\mathrm{OPC}^{*}$ & 3300 & 200 & 330 & 3.15 & 21.7 & 5.7 & 3.2 & 63.1 & 2.8 & 2.2 & 2.44 \\
\hline
\end{tabular}

\subsection{Experimental Plan}

Table 4 details the mixing compositions of the cement pastes used in this study. For the plain cement paste (referred to as Plain) mixture, only cement was used, and the water-to-cement ratio was set at 0.3 . Such a minimal water-to-cement ratio was selected to help generate a large amount of hydration products for examining the strength and hydration characteristics. For the red mud mixtures, the addition of LRM and LRM + S were 10 and $20 \%$ by weight of cement. We used $10 \%$ and $20 \%$ LRM because the strength sharply decreased when LRM content in the cement was increased beyond $20 \%$. This was also confirmed by our preliminary experiments. To prepare the cement pastes, mixing was performed using a mortar mixer for $4 \mathrm{~min}$.

Table 4. Mixture design.

\begin{tabular}{|c|c|c|c|c|}
\hline \multirow{2}{*}{ Mix ID } & \multirow{2}{*}{ Cement (wt\%) } & \multirow{2}{*}{ Water $(w t \%)$} & \multicolumn{2}{|c|}{ Extra Discount Red Mud (wt \%) } \\
\hline & & & LRM & $\mathrm{LRM}+\mathrm{S}$ \\
\hline Plain & \multirow{5}{*}{100} & \multirow{5}{*}{30} & - & - \\
\hline LRM-10 & & & 10 & - \\
\hline LRM-20 & & & 20 & - \\
\hline $\mathrm{LRM}+\mathrm{S}-10$ & & & - & 10 \\
\hline $\mathrm{LRM}+\mathrm{S}-20$ & & & - & 20 \\
\hline
\end{tabular}

\subsection{Methods}

A multichannel microcalorimeter was used to measure the flow of heat of hydration. When LRM and LRM + S were used, they were added to water and then mixed with cement [14]. The flow of heat of hydration was measured from the moment when the water was first mixed with cement up until $72 \mathrm{~h}$ had elapsed.

Samples for the compressive-strength measurement were fabricated with dimensions of $40 \mathrm{~mm} \times 40 \mathrm{~mm} \times 160 \mathrm{~mm}$. They were removed from the mold after a 24-h curing process at 
a temperature of $20 \pm 2{ }^{\circ} \mathrm{C}$ and relative humidity of $50 \%$ and then cured under these same temperature and humidity conditions until they reached the desired age for obtaining the compressive-strength measurements. Compressive strength was measured under the same conditions for three samples of each mixture, and the average compressive strength was obtained at ages of $1,3,7$, and $28 \mathrm{~d}$. The compressive strength measurement process was in accordance with the standards of ASTM C 349 (Universal Testing Machine).

To examine the hydration products, the samples were collected at various ages $(1 \mathrm{~h}$ and $1,3,7$, and $28 \mathrm{~d}$ ) and immersed in ethyl alcohol for $24 \mathrm{~h}$ to stop hydration. They were then dried in an oven at $80^{\circ} \mathrm{C}$ for $24 \mathrm{~h}$. The dried samples were crushed and sifted through a 200-mesh sieve for XRD analysis $[15,16]$. The XRD analysis mainly compared the availability of portlandite among the hydration products to analyze the hydration characteristics of cement using LRM before and after neutralization.

\section{Results and Discussion}

\subsection{Heat of Hydration}

Heat of hydration of cement can be classified into heat of hydration over time and accumulated heat of hydration. In general, the heat of hydration over time is used to indirectly predict the setting time of the cement. Similarly, the accumulated heat of hydration is used to predict the initial compressive strength of the cement paste [17].

Figure 3a shows the evolution of heat of hydration over time. In general, the heat of hydration of cement paste has two peaks. The first peak is generally related to the formation of ettringite (AFt) $[18,19]$. The second peak is related to the hydration of $C_{3} S$ and $C_{2} S$, as well as the formation of C-S-H and portlandite [15]. In this study, the first and second peaks occurred in $0.1-0.3 \mathrm{~h}$ and $15-54 \mathrm{~h}$, respectively.

Figure $3 \mathrm{~b}$ shows the first peaks. The first peak for Plain occurred at approximately $0.1 \mathrm{~h}$. The first peaks of the cement paste samples with LRM and LRM + S occurred at approximately 0.15 and $0.1 \mathrm{~h}$, respectively. Compared to that of Plain, the first peaks of the LRM and LRM + S samples were similar and delayed, respectively. This indicates that the hydration rate related to the formation of ettringite can be improved by neutralizing the LRM with sulfuric acid.

Figure 3c shows the second peaks. The second peak of Plain occurred at approximately $15 \mathrm{~h}$. The second peaks of the paste samples with LRM occurred at 24 and $54 \mathrm{~h}$ for LRM10 and LRM20, respectively. They were delayed by 1.6-3.6 times in comparison with that of the second peak of Plain. Conversely, the second peaks of the paste samples with LRM $+\mathrm{S}$ were similar to that of Plain regardless of the amount of additive. This indicates that the hydration of $C_{3} S$ and $C_{2} S$, as well as the formation of $\mathrm{C}-\mathrm{S}-\mathrm{H}$ and portlandite, are similar to those processes that occur in Plain when LRM is neutralized with sulfuric acid and added to the cement paste. 


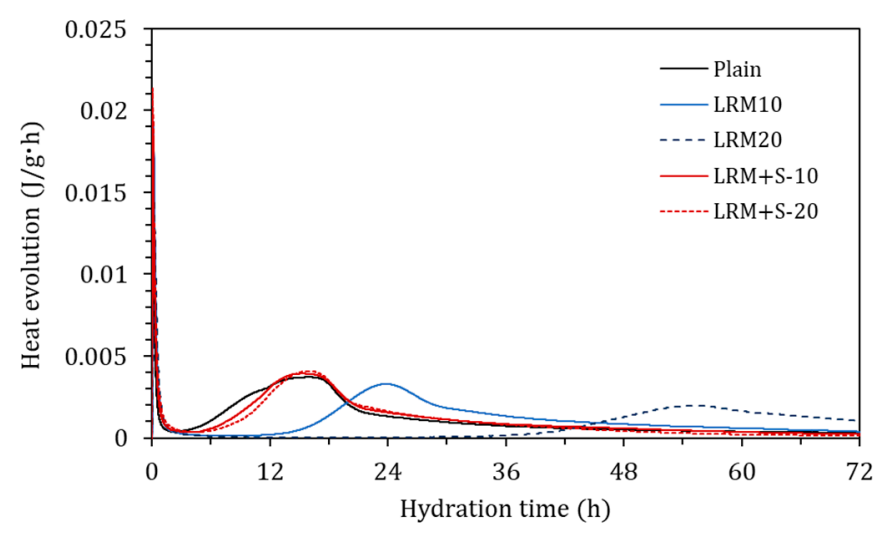

(a) Heat evolution rate

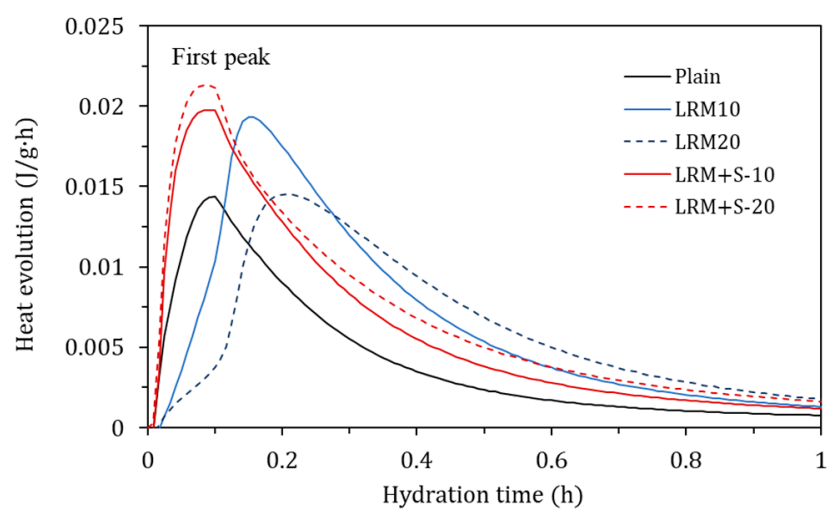

(b) First peak of the heat of hydration

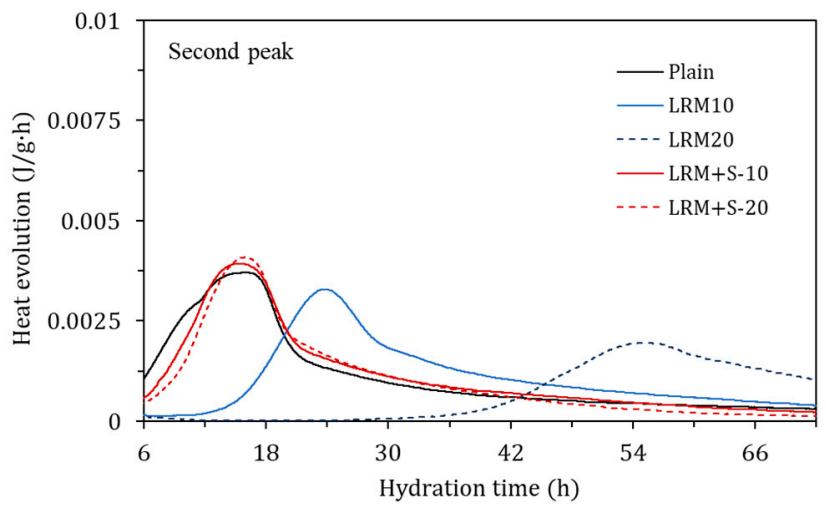

(c) Second peak of the heat of hydration

Figure 3. Heat evolution rates of the various cement paste samples.

Figure 4 shows the accumulated heat of hydration over time. The accumulated heat of hydration of Plain over $72 \mathrm{~h}$ was $9.8 \mathrm{~J} / \mathrm{g}$. When LRM was added, the accumulated heat of hydration was found to be $9.5 \mathrm{~J} / \mathrm{g}$ for LRM-10 and $6.4 \mathrm{~J} / \mathrm{g}$ for LRM-20. In the case of LRM $+\mathrm{S}$, the accumulated heat of hydration was $10.2 \mathrm{~J} / \mathrm{g}$ for LRM + S-10 and 9.5 J/g for LRM + S-20. This indicates that an initial strength higher than that of LRM can be achieved when LRM is neutralized with sulfuric acid and added to cement paste, regardless of the added amount. 


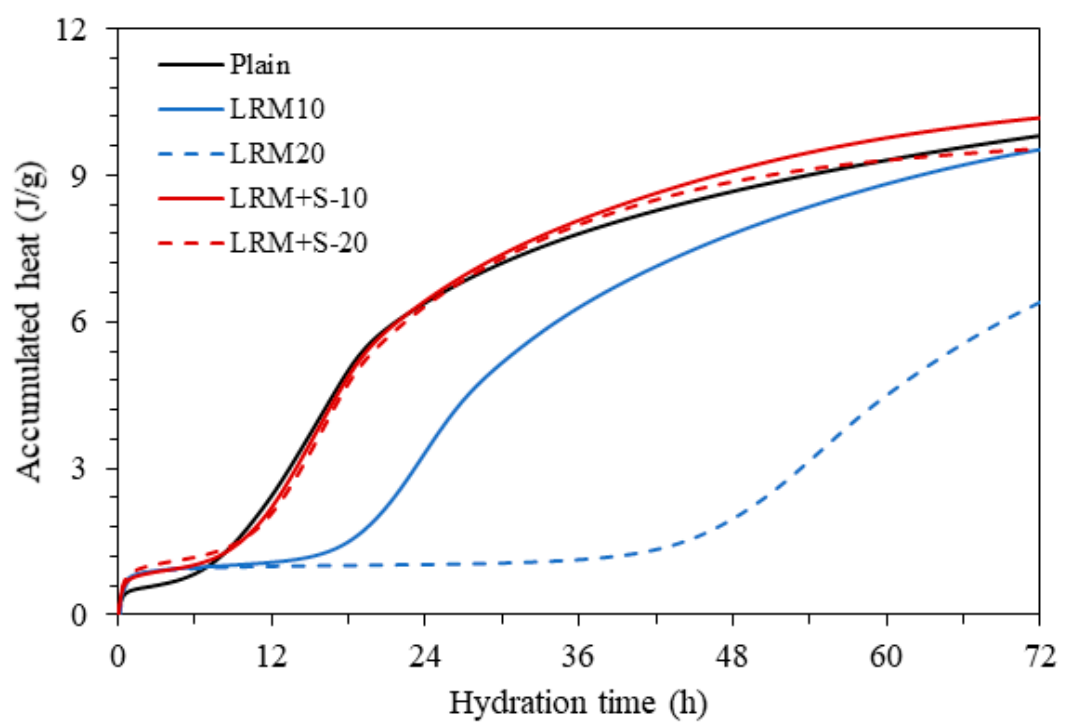

Figure 4. Accumulation of heat for the various cement paste samples.

\subsection{Compressive Strength}

Figure 5 presents the compressive strength measurement results. The compressive strength of Plain at the age of $28 \mathrm{~d}$ was $61 \mathrm{MPa}$. The compressive strengths of LRM10 and LRM20 at the same age were 38 and $34 \mathrm{MPa}$, respectively, which were $38 \%$ and $44 \%$ lower in comparison to that of Plain.

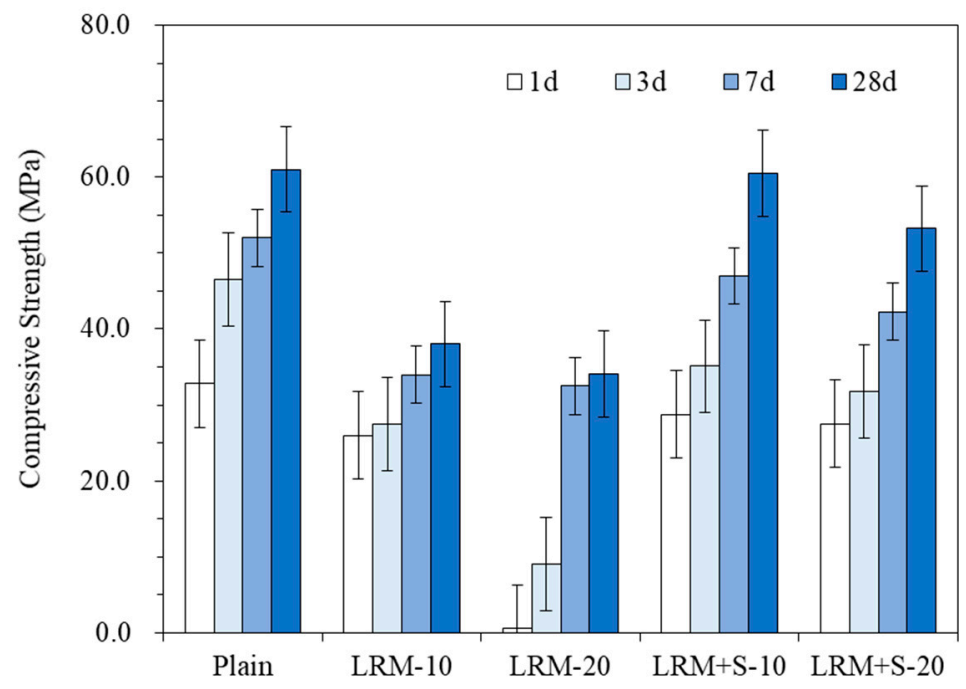

Figure 5. Effects of LRM and LRM + S on the compressive strength of the cement paste.

Conversely, the compressive strengths of LRM + S10 and LRM + S20 at the same age were 60 and $53 \mathrm{MPa}$, respectively, which were $59 \%$ and $56 \%$ higher in comparison with that of the LRM samples.

Figure 6 plots the evolution of compressive strength ratios of the LRM and LRM $+\mathrm{S}$ samples in comparison with the compressive strength of Plain. As the amount of LRM added increased, the strength ratio decreased. Before $7 \mathrm{~d}$, the difference in strength ratio between LRM10 and LRM20 increased as the age decreased. This appears to have occurred because LRM had a negative effect on the initial hydration of cement, resulting in a negative effect on the strength ratio, which increased as the amount of additive increased. In particular, the strength degradation of LRM20 at ages of 1 and $3 \mathrm{~d}$ was noticeable, which agrees with the result that the accumulated heat of hydration of LRM20 was relatively low, as shown in Figure 4. The negative effects of LRM on the initial hydration also appear to have affected the compressive strength at the age of $28 \mathrm{~d}$. In previous studies, the use of 
red mud was limited to $10 \%$ or less for the construction industry because red mud does not undergo pozzolanic reactions $[1,20,21]$.

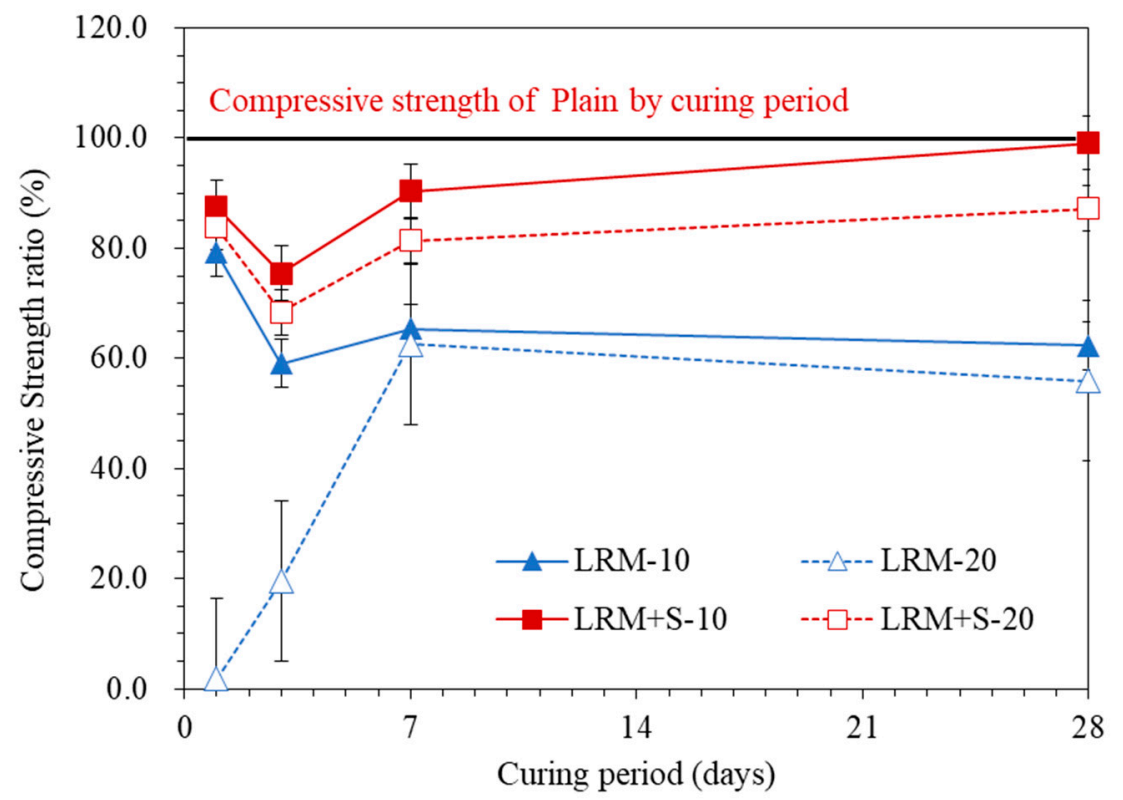

Figure 6. Effects of LRM and LRM $+\mathrm{S}$ on the compressive strength ratio of the cement paste.

In the case of LRM $+S$, the strength ratio decreased as the amount of additive increased. As opposed to the LRM samples, the differences in strength ratios between LRM + S10 and LRM + S20 at all ages were similar. Moreover, the negative effect on the initial hydration of the cement decreased in comparison with LRM and the strength ratio slightly increased at the age of $28 \mathrm{~d}$. The fine particles of red mud appeared to have had a positive effect on the compressive strength as they filled the matrix [1,22]. The compressive strength of LRM + S10 at the age of $28 \mathrm{~d}$ was similar to that of Plain, indicating that the content of red mud can be increased further than the previously presented value (by an amount of less than $10 \%$ ) by neutralizing the red mud [1,21].

\subsection{Microstructure}

Figure 7 presents the XRD results obtained for different ages. Portlandite is the main hydration product of cement, and calcium silicate is the unhydrated substance [23].

As shown in Figure $7 \mathrm{a}$, portlandite, the main hydration product, was observed at $2 \theta=18.1^{\circ}$, $34.1^{\circ}$, and $47.2^{\circ}$ at $1 \mathrm{~h}$ for Plain. In general, portlandite is continuously observed in cement paste after watering. However, in the case of the cement paste with added LRM and LRM $+S$, the main peak of portlandite was not observed at $2 \theta=18.1^{\circ}$. This appears to be due to the presence of Na-based compounds in red mud; this agrees with the results of a previous study wherein portlandite was not initially observed when Na-based compounds were added to cement paste [24]. In addition, owing to the first peak appearing $1 \mathrm{~h}$ earlier in the heat of hydration result (Figure 3a), ettringite was observed in $1 \mathrm{~h}$ even in the XRD result.

Figure $7 \mathrm{~b}$ shows that the cement paste with LRM did not exhibit the $\mathrm{Ca}(\mathrm{OH})_{2}$ peak at $2 \theta=18^{\circ}$ and $1 \mathrm{~d}$, but the peak was observed at $2 \theta=18^{\circ}$ when $\mathrm{LRM}+\mathrm{S}$ was added. As LRM $+\mathrm{S}$ was prepared by neutralizing LRM with sulfuric acid, $\mathrm{Na}_{2} \mathrm{SO}_{4}$ was observed in the XRD pattern analysis. According to a previous study, the addition of a small amount of sulfate to cement paste delays the hydration of the cement, whereas the addition of a large amount of sulfate accelerates it [25]. This agrees with our results, thereby confirming that the cement paste with LRM + S exhibited a compressive strength closer to that of Plain in comparison with the cement paste with LRM at the age of $1 \mathrm{~d}$, and that the cement paste with LRM did not exhibit a similar strength. 


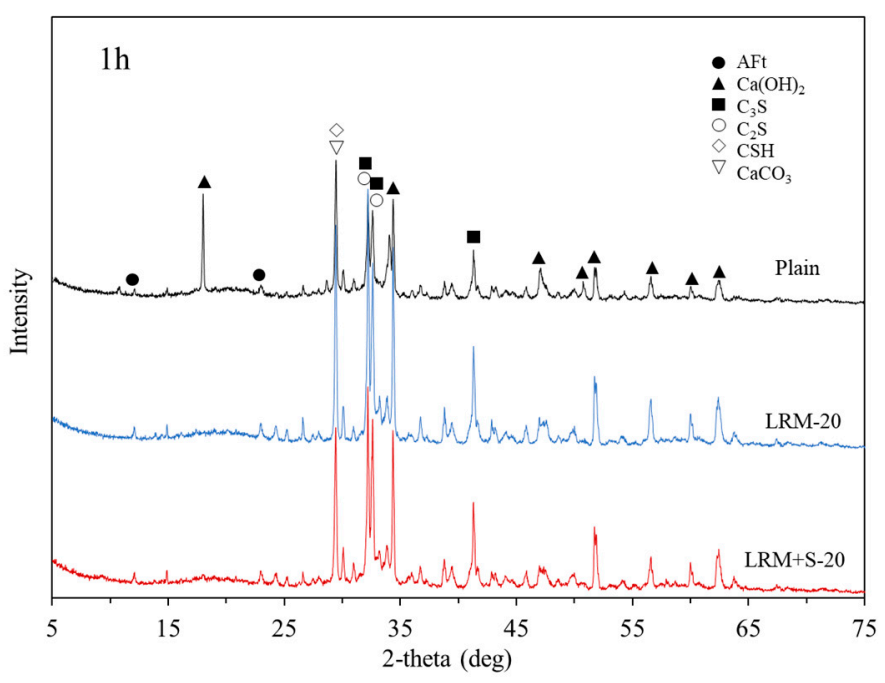

(a) $1 \mathrm{~h}$

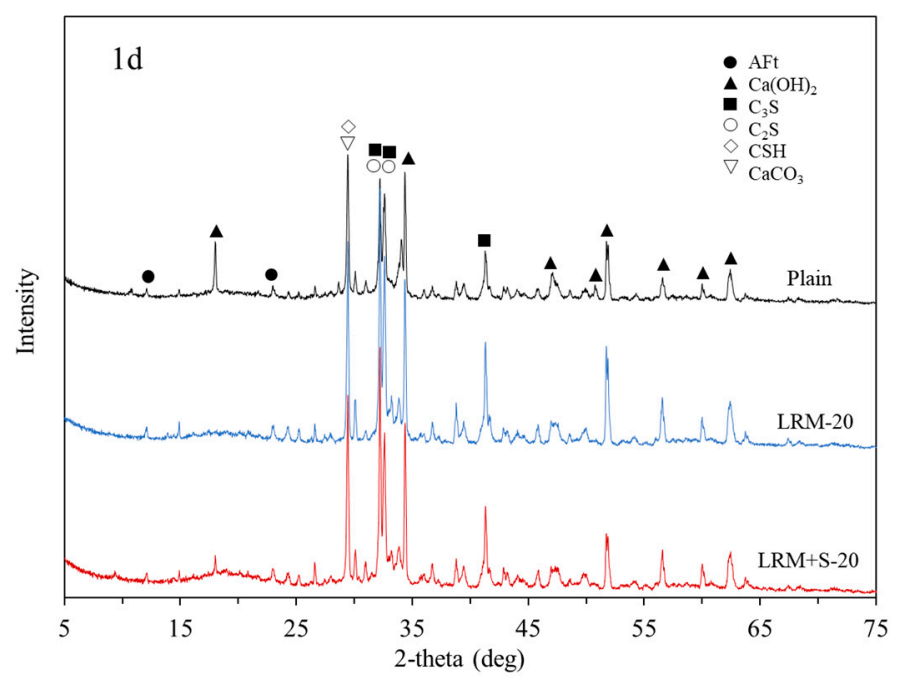

(b) $1 \mathrm{~d}$

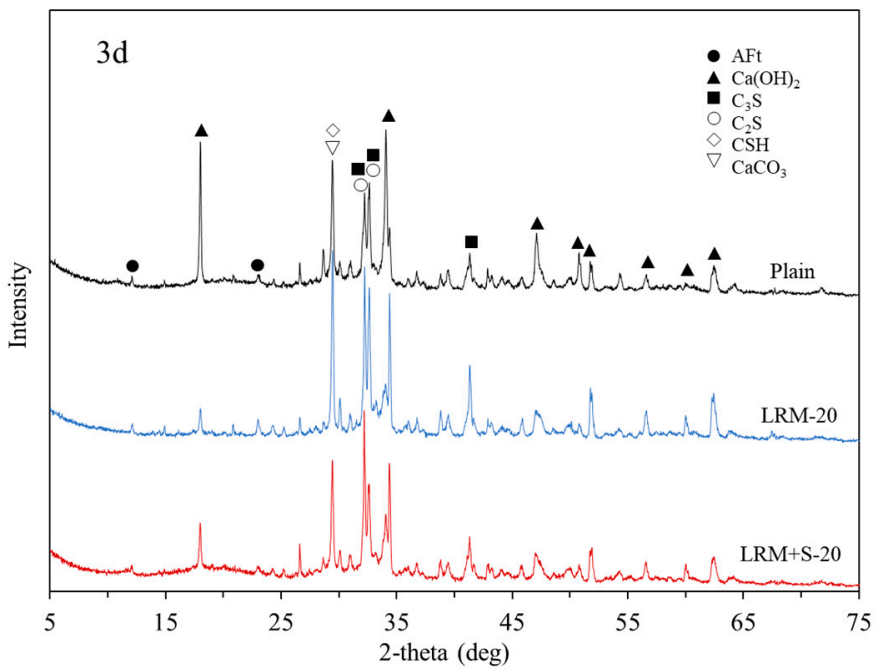

(c) $3 \mathrm{~d}$

Figure 7. Cont. 


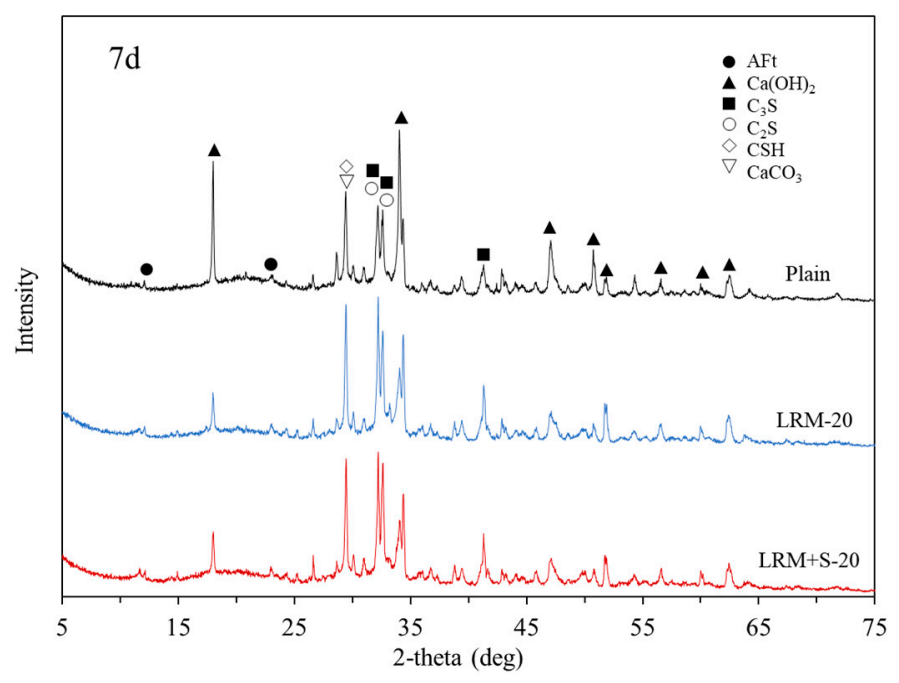

(d) $7 \mathrm{~d}$

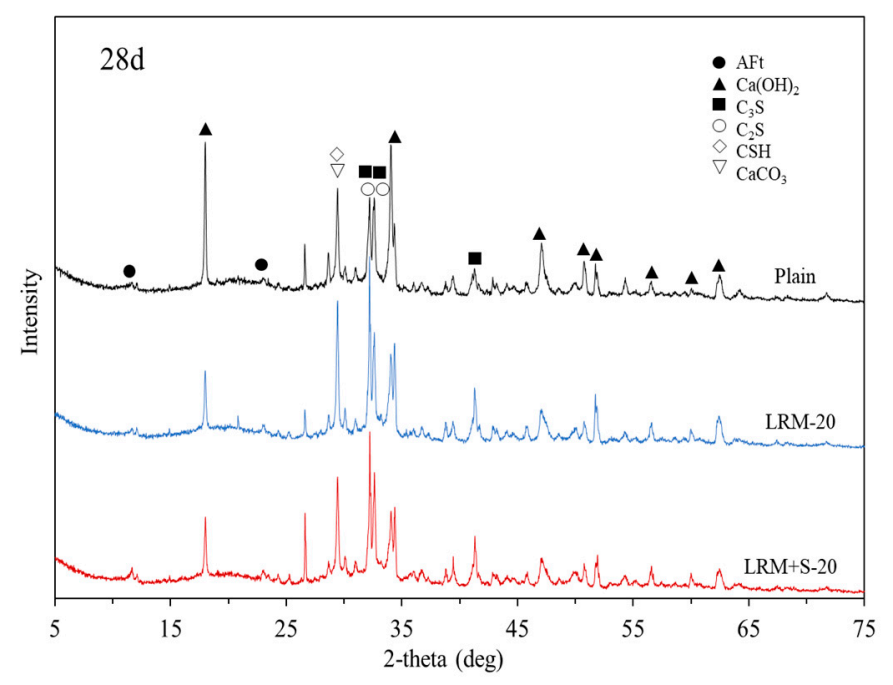

(e) $28 \mathrm{~d}$

Figure 7. XRD spectrum results of the mixtures with red mud at varying ages.

In Figure 7c,d, the cement paste with LRM exhibited the $\mathrm{Ca}(\mathrm{OH})_{2}$ peak at $2 \theta=18^{\circ}$ at 3 and $7 \mathrm{~d}$. This agrees with the compressive-strength results, thereby confirming that the strength of LRM-20 sharply increased from $3 \mathrm{~d}$ onward. Additionally, the hydration of $\mathrm{C}_{3} \mathrm{~S}$ and $\mathrm{C}_{2} \mathrm{~S}$, as well as the generation of C-S-H and portlandite, occurred while the second peak was observed in the heat of hydration results.

Figure 7e shows that calcite $\left(\mathrm{CaCO}_{3}\right)$, portlandite $\left(\mathrm{Ca}(\mathrm{OH})_{2}\right)$, and calcium silicate hydrate $(\mathrm{C}-\mathrm{S}-\mathrm{H})$, which serve to develop strength, were observed in Plain, LRM, and LRM + S at the age of $28 \mathrm{~d}$.

When red mud was added to cement concrete and XRD analysis was conducted, no new phase was observed even when LRM and LRM + S were added to the cement paste, unlike in a previous study [24].

\section{Conclusions}

In this study, neutralized red mud was prepared by neutralizing liquefied red mud (LRM) with sulfuric acid to remediate the issue of strength degradation observed in cementitious materials when mixed with highly alkaline LRM. The heat of hydration, compressive strength, and hydration products 
of LRM and LRM + S cement pastes were compared using X-ray diffraction (XRD), and the following conclusions were drawn:

(1) The heat of hydration measurement results indicated that the maximum heat of hydration peak exhibited a low calorific value and was delayed for the cement paste with LRM in comparison with Plain. Conversely, the heat of hydration peak of the cement paste containing LRM + S was found to be similar to that of Plain.

(2) The compressive strength at the age of $28 \mathrm{~d}$ for the cement paste with LRM was found to be as low as $55 \%$ of the compressive strength of Plain, whereas the cement paste with LRM $+\mathrm{S}$ showed a strength ratio as high as $99 \%$.

(3) In the XRD analysis, the cement paste with $20 \% \mathrm{LRM}+\mathrm{S}$, unlike in the case of LRM sample, showed a $\mathrm{Ca}(\mathrm{OH})_{2}$ peak after only $1 \mathrm{~h}$, similar to the case of Plain. In addition, no new products due to the addition of red mud were observed.

(4) As the compressive strength of LRM + S10 at $28 \mathrm{~d}$ was similar to that of Plain, it can be assumed that (under the same conditions as in this study) up to $10 \%$ neutralized red mud can be added to cement pastes without affecting its strength.

Therefore, the results of our study show that red mud could be considered as a viable construction material if it is suitably processed by reducing its alkalinity. In addition, we are testing other acids, and the results will be reported in a future work. We also note that it is necessary to further clarify the results reported in this paper through analysis of the hydration products.

Author Contributions: Conceptualization, S.K., H.K. and B.L.; Methodology, S.K., H.K. and B.L.; Software, H.K.; Validation, S.K. and B.L.; Formal Analysis, S.K., H.K. and B.L.; Investigation, S.K., H.K. and B.L.; Resources, H.K. and B.L.; Data Curation, H.K.; Writing-Original Draft Preparation, H.K.; Writing-Review \& Editing, H.K.; Visualization, H.K.; Supervision, S.K.; Project Administration, S.K.; Funding Acquisition, S.K. All authors have read and agreed to the published version of the manuscript.

Funding: This work was supported by the Korea Environmental Industry and Technology Institute (KEITI) and funded by the Ministry of Environment (No. 2019002750002).

Conflicts of Interest: The authors declare no conflict of interest.

\section{References}

1. Ribeiro, D.V.; Labrincha, J.A.; Morelli, M.R. Potential use of natural red mud as pozzolan for Portland cement. Mater. Res. 2011, 14, 60-66. [CrossRef]

2. Li, J.; Xu, L.; Sun, P.; Zhai, P.; Chen, X.; Zhang, H.; Zhang, Z.-S.; Zhu, W. Novel application of red mud: Facile hydrothermal-thermal conversion synthesis of hierarchical porous $\mathrm{AlOOH}$ and $\mathrm{Al} 2 \mathrm{O} 3$ microspheres as adsorbents for dye removal. Chem. Eng. J. 2017, 321, 622-634. [CrossRef]

3. Yang, J.; Xiao, B. Development of unsintered construction materials from red mud wastes produced in the sintering alumina process. Constr. Build. Mater. 2008, 22, 2299-2307. [CrossRef]

4. Nath, H.; Sahoo, A. A study on the characterization of red mud. Int. J. Appl. Bioeng. 2014, 8, 1-4. [CrossRef]

5. Dodoo-Arhin, D.; Nuamah, R.A.; Agyei-Tuffour, B.; Obada, D.O.; Yaya, A. Awaso bauxite red mud-cement based composites: Characterisation for pavement applications. Case Stud. Constr. Mater. 2017, 7, 45-55. [CrossRef]

6. Amritphale, S.; Anshul, A.; Chandra, N.; Ramakrishnan, N. A novel process for making radiopaque materials using bauxite-Red mud. J. Eur. Ceram. Soc. 2007, 27, 1945-1951. [CrossRef]

7. He, J.; Jie, Y.; Zhang, J.; Yu, Y.; Zhang, G. Synthesis and characterization of red mud and rice husk ash-based geopolymer composites. Cem. Concr. Compos. 2013, 37, 108-118. [CrossRef]

8. Enforcement Regulations of Waste Management Act. Available online: http://www.law.go.kr/\%EB\%B2\%95\% EB\%A0\%B9/\%ED\%8F\%90\%EA\%B8\%B0\%EB\%AC\%BC\%EA\%B4\%80\%EB\%A6\%AC\%EB\%B2\%95\%EC\% $8 \mathrm{~B} \% 9 \mathrm{C} \% \mathrm{ED} \% 96 \% 89 \% \mathrm{EA} \% \mathrm{~B} 7 \% 9 \mathrm{C} \% \mathrm{EC} \% \mathrm{~B} 9 \% 99$ (accessed on 16 September 2020).

9. Ribeiro, D.V.; Labrincha, J.A.; Morelli, M.R. Use of red mud as addition for portland cement mortars. J. Mater. Sci. Eng. 2010, 4, 1-8. 
10. Liu, X.; Zhang, N.; Sun, H.; Zhang, J.; Li, L. Structural investigation relating to the cementitious activity of bauxite residue-Red mud. Cem. Concr. Res. 2011, 41, 847-853. [CrossRef]

11. Choe, G.; Kang, S.; Kang, H. Mechanical Properties of Concrete Containing Liquefied Red Mud Subjected to Uniaxial Compression Loads. Materials 2020, 13, 854. [CrossRef]

12. Li, Z.; Afshinnia, K.; Rangaraju, P.R. Effect of alkali content of cement on properties of high performance cementitious mortar. Constr. Build. Mater. 2016, 102, 631-639. [CrossRef]

13. Choe, G.; Kang, S.; Kang, H. Characterization of Slag Cement Mortar Containing Nonthermally Treated Dried Red Mud. Appl. Sci. 2019, 9, 2510. [CrossRef]

14. Hu, X.; Shi, C.; Shi, Z.; Tong, B.; Wang, D. Early age shrinkage and heat of hydration of cement-fly ash-slag ternary blends. Constr. Build. Mater. 2017, 153, 857-865. [CrossRef]

15. Wang, Y.; He, F.; Wang, J.; Hu, Q. Comparison of Effects of Sodium Bicarbonate and Sodium Carbonate on the Hydration and Properties of Portland Cement Paste. Materials 2019, 12, 1033. [CrossRef]

16. Saraya, M.E. Stopping of cement hydration by various methods. HBRC J. 2010, 6, 36-60.

17. Kim, H.Y. Urea additives for reduction of hydration heat in cement composites. Constr. Build. Mater. 2017, 156, 790-798. [CrossRef]

18. Kunther, W.; Lothenbach, B.; Scrivener, K. Influence of bicarbonate ions on the deterioration of mortar bars in sulfate solutions. Cem. Concr. Res. 2013, 44, 77-86. [CrossRef]

19. Kerui, Y.; Caiwen, Z.; Zhigang, L. The influence of calcium lignosulphonate-sodium bicarbonate on the status of ettringite crystallization in fly ash cement paste. Cem. Concr. Res. 2002, 32, 51-56. [CrossRef]

20. Ortega, J.; Cabeza, M.; Tenza-Abril, A.J.; Real, T.; Climent, M.Á.; Sánchez, I. Effects of Red Mud Addition in the Microstructure, Durability and Mechanical Performance of Cement Mortars. Appl. Sci. 2019, 9, 984. [CrossRef]

21. Senff, L.; Modolo, R.; Silva, A.S.; Ferreira, V.; Hotza, D.; Labrincha, J.A. Influence of red mud addition on rheological behavior and hardened properties of mortars. Constr. Build. Mater. 2014, 65, 84-91. [CrossRef]

22. Liu, R.-X.; Poon, C.-S. Utilization of red mud derived from bauxite in self-compacting concrete. J. Clean. Prod. 2016, 112, 384-391. [CrossRef]

23. He, Y.; Zhang, X.; Liu, S.; Hooton, R.; Ji, T.; Kong, Y. Impacts of sulphates on rheological property and hydration performance of cement paste in the function of polycarboxylate superplasticizer. Constr. Build. Mater. 2020, 256, 119428. [CrossRef]

24. Sutar, H.; Murmu, R.; Roy, D.; Mishra, S.C. Effect of Red Mud (RM) Reinforcement on Physio-Chemical Characteristics of Ordinary Portland Slag Cement (OPSC) Mortar. Adv. Mater. Phys. Chem. 2016, 6, 231-238. [CrossRef]

25. Niu, M.; Li, G.; Zhang, J.; Cao, L. Preparation of alkali-free liquid accelerator based on aluminum sulfate and its accelerating mechanism on the hydration of cement pastes. Constr. Build. Mater. 2020, 253, 119246. [CrossRef]

(C) 2020 by the authors. Licensee MDPI, Basel, Switzerland. This article is an open access article distributed under the terms and conditions of the Creative Commons Attribution (CC BY) license (http://creativecommons.org/licenses/by/4.0/). 